\title{
SISTEM PAKAR MENDETEKSI KERUSAKAN PADA MOBIL SUZUKI DENGAN ALGORITMA RETE
}

\author{
Ahmad Fajri ${ }^{1)}$ dan Prihandoko ${ }^{2)}$ \\ ${ }^{1,2}$ Universitas AMIKOM Yogyakarta, Fakultas Pascasarjana Teknik Informatika, Teknik Informatika \\ ${ }^{1,2}$ Ngringin, Condongcatur, Kec. Depok, Kabupaten Sleman, Daerah Istimewa Yogyakarta 55281 \\ E-mail: ahmad16fajri@gmail.com ${ }^{1)}$, pri@staff.gunadarma.ac.id ${ }^{2)}$
}

\begin{abstract}
ABSTRAK
Penelitian ini dilakukan bertujuan untuk membuat Sistem Pakar Mendeteksi Kerusakan pada mobil Suzuki Dengan Algoritma RETE. Alat bantu pengembangan sistem yang digunakan flowchart dan Algoritma RETE dengan menggunakan bahasa pemrograman $P H P$ serta database MySQL. Maka dihasilkan sebuah Sistem Pakar mendeteksi kerusakan mobil Suzuki Dengan Algoritma RETE yang dapat memberi kemudahan pada para mekanik PT. Samekarindo Indah yang ingin melakukan diagnosa kerusakan mobil Suzuki dengan menggunakan bahasa pemrograman PHP dan MySQL.
\end{abstract}

Kata kunci: Sistem Pakar, Algoritma RETE, PHP, MySQL

\section{PENDAHULUAN}

Perusahaan PT. Samekarindo Indah adalah perusahaan yang sangat terbuka bagi pelajar-pelajar khususnya pelajar dibidang Mekanik. Mekanik yang banyak dipekerjakan di perusahaan ini adalah hasil dari pelatihan standarisasi khusus untuk mobil Suzuki (Sekolah Menengah Kejuruan Suzuki Malang). Tetapi ada juga mekanik yang dipekerjakan dari lulusan jurusan Mekanik kemudian mekanik tersebut dilatih melalui pelatihan atau training standarisasi servis produk.

Mengingat disebuah perusahaan mobil yang terus menerus berkembang khususnya pada keluaran jenis dan tipe mobil maka pelatihan atau training standarisasi produk ini bisa saja terlewatkan oleh seorang mekanik dikarenakan jangka waktu yang telah lewat dari pengeluaran mobil tersebut. Sedangkan pelatihan atau training servis produk suatu mobil hanya pada saat masa mobil itu baru dikeluarkan atau baru diperkenalkan ke masyarakat luas sehingga bagi mekanik yang sudah mendapatkan pelatihan suatu produk mobil dengan jangka waktu yang lama pengetahuan tersebut bisa terlupakan dan bagi mekanik yang baru tetapi training produk sudah terlaksanakan maka akan tertinggal pengetahuan sedangkan produk sudah banyak terjual dan sangat banyak konsumen yang melakukan servis dengan produk tersebut.

Dari sinilah penulis menilai bahwa sangat perlu untuk menyimpan suatu pengetahuan servis ini agar bisa digunakan bagi mekanik yang baru dan dapat membantu mekanik yang lama saat mereka lupa akan pengetahuan servis produk tersebut. Penulis menilai pengetahuan tentang servis produk ini sangat baik disimpan berbentuk program sistem pakar. Sistem pakar adalah salah satu bagian dari kecerdasan buatan yang mengandung pengetahuan dan pengalaman yang dimasukkan oleh satu banyak pakar ke dalam suatu area pengetahuan tertentu sehingga setiap orang dapat menggunakannya untuk memecahkan berbagai masalah yang bersifat spesifik dalam hal ini adalah permasalahan pada kinerja mobil.

Bagi konsumen yang memiliki mobil kerusakan pada mobil salah satunya terjadi akibat kelalaian dalam melakukan perawatan dan bisa pula terjadi karena keadaan alamiah. Kerusakan mobil akan disadari pemilik mobil setelah mobil tidak dapat beroperasi sebagaimana mestinya atau sebagaimana biasanya. Jika pemilik mobil telah mengalami hal ini maka merekapun biasanya akan memperbaiki mobil mereka di bengkel servis Suzuki dan para mekanik yang ada akan memperbaiki mobil yang bermasalah tersebut.

Diantara sekian banyak merk mobil yang beredar saat ini, mobil Suzuki salah satu yang paling banyak digemari oleh konsumen selain Toyota dan daihatsu. Dengan persaingan dalam penjualan mobil, team mekanik Suzuki R4 juga bersaing dalam bidang pelayanan perbaikan. Dari hal tersebut maka penulis akan mengambil suatu pengetahuan atas servis mobil Suzuki untuk dijadikan suatu program sistem pakar diagnosis kerusakan mobil suzuki.

Gambaran diatas menjadi suatu pertimbangan bagi penulis untuk membuat "Sistem Pakar Mendekteksi Kerusakan Pada Mobil Suzuki Dengan Algoritma Rete" sebagai upaya untuk mengembangkan cara menemukan kerusakan pada mobil Suzuki melalui sistem komputer. Diharapkan sistem pakar yang dibuat dapat membantu para mekanik untuk menyelesaikan permasalah perbaikan servis mobil konsumen yang bermasalah.

\section{RUANG LINGKUP}

Dalam penyusunan tesis agar menjadi mudah untuk dimengerti, maka akan diterapkan beberapa batasan masalah. Selain itu maksud dari pembatasan masalah adalah karena keterbatasan waktu dan ilmu pengetahuan dalam melakukan penelitian dan 
pengumpulan data secara terperinci. Batasan-batasan masalah antara lain :

1. Pembangunan sistem pakar menggunakan Metode Inferensi Algoritma RETE .

2. Metode yang diterapkan pada suatu model program dalam bahasa pemprograman PHP sebagai pramework untuk pemprograman sistem pakar diagnosis kerusakan mobil Suzuki.

3. Diagnosis terfokus hanya pada bagian mesin saja.

\section{BAHAN DAN METODE}

\subsection{Penjelasan Bahan}

Sistem pakar adalah sistem yang berusaha mengadopsi pengetahuan manusia ke komputer yang dirancang untuk memodelkan kemampuan menyelesaikan masalah seperti layaknya seorang pakar. Dengan sistem pakar ini, orang awam pun dapat menyelesaikan masalahnya atau hanya sekedar mencari suatu informasi berkualitas yang sebenarnya hanya dapat diperoleh dengan bantuan para ahli di bidangnya.

Tujuan dari sebuah sistem pakar adalah untuk mentransfer kepakaran yang dimiliki seorang pakar kedalam komputer, dan kemudian kepada orang lain (non expert).

Ada beberapa alasan mendasar mengapa sistem pakar dikembangkan untuk menggantikan seorang pakar, diantaranya:

1. Dapat menyediakan kepakaran setiap waktu dan di berbagai lokasi.

2. Secara otomatis mengerjakan tugas-tugas rutin yang membutuhkan seorang pakar.

3. Seorang pakar akan pensiun atau pergi.

4. Seorang pakar adalah mahal.

5. Kepakaran dibutuhkan juga pada lingkungan yang tidak bersahabat (hostile environtment).

Menurut Kusrini (2008) arsitektur dasar dari sistem pakar dapat dilihat pada gambar 1 berikut ini:

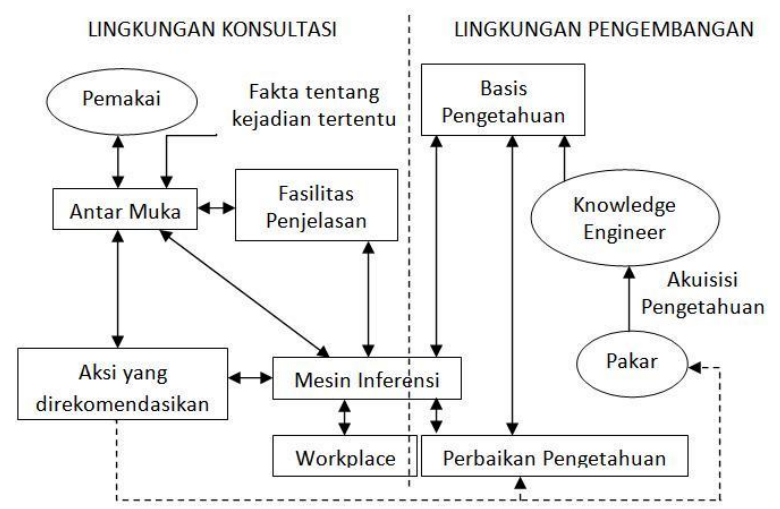

Gambar 1. Arsitektur Sistem Pakar

\subsection{Algoritma RETE}

Algoritma Rete adalah algoritma pattern matching yang dirancang oleh Charles L. Forgy. Algoritma Rete adalah algoritma yang sangat efisien untuk mencocokkan fakta dengan pola dalam aturan. Sebuah ruleset adalah sebuah knowledge base yang terdiri dari satu atau beberapa aturan. Setiap aturan dalam ruleset melambangkan sebagian pengetahuan. Aturan-aturan biasanya dalam bentuk jika-maka. Ketika aturan jika maka cocok untuk algoritma Rete, maka mereka disebut aturan Rete. Berikut adalah contoh aturan Rete: Jika orang, umur $>60$, maka set status = "lansia".

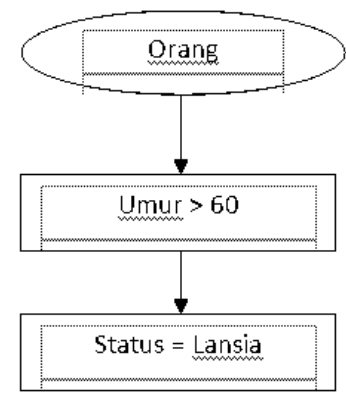

\section{Gambar 2. Skema Algoritma RETE}

Dari contoh tersebut, dibutuhkan data untuk melihat apakah status orang ini lansia atau tidak, data ini disebut fakta. Sebuah ruleset yang lengkap dibutuhkan dalam rule engine untuk memproses fakta-fakta yang ada. Rule engine mencocokkan setiap aturan di dalam ruleset dengan fakta-fakta yang diberikan untuk memutuskan apakah akan melaksanakan aturan tersebut atau tidak. Hal ini disebut pattern matching dan proses ini dilakukan berulang kali. Di tiap siklus, daftar fakta yang ada bisa dimodifikasi seperti fakta baru bisa ditambahkan ke dalam daftar yang ada atau fakta yang lama bisa dihapus dari daftar. Perubahan ini bisa membuat aturan-aturan yang sebelumnya tidak terpenuhi menjadi terpenuhi. Di setiap siklus, setiap aturan yang terpenuhi harus tetap disimpan dan tetap updated. Pada kebanyakan kasus, aturan yang dieksekusi hanya akan mempengaruhi sedikit fakta dalam daftar. Hal ini disebut temporal redundancy. Jika rule engine memeriksa setiap aturan untuk mencari fakta yang cocok, meskipun kebanyakan dari aturan tersebut tidak dimodifikasi, maka hal ini tentu akan sangat memperlambat proses. Komputasi yang tidak perlu ini bisa dihindari dengan mengingat apa yang sudah dicocokkan di tiap siklus, lalu hanya melakukan komputasi pada perubahan yang diperlukan.

Jaringan Rete adalah suatu graph yang terdiri dari nodes yang melambangkan pola dalam kondisi aturan. Nodes ini bersifat seperti filter, menguji coba input yang masuk dan hanya meloloskan input yang lolos uji coba. Jaringan Rete terdiri dari dua bagian, yaitu jaringan alpha dan jaringan beta. Jaringan alpha terdiri dari nodes yang disebut alpha nodes. Jaringan beta juga terdiri dari nodes yang disebut beta nodes. Jaringan Rete dimulai dari root node yang disebut Rete node. Root node diikuti oleh kind nodes. Kind node adalah jenis dari tipe data fakta. Kemudian alphanodes akan diciptakan untuk setiap pola dan terkoneksi dengan kind node yang bersangkutan. Setiap alpha node berhubungan dengan memory yang disebut alpha memory. Alpha memory 
digunakan untuk mengingat fakta yang cocok. Alpha nodes lalu akan digabungkan di dalam beta nodes. Beta node hanya menerima dua input. Sehingga jika ada tiga alpha nodes, dua alpha nodes akan digabungkan terlebih dahulu ke dalam beta node, lalu alpha node ketiga akan digabungkan dengan beta node yang telahdibuat dan akan menjadi beta node baru. Dengan demikian beta nodes mendukung partial matching. Setiap beta node memiliki memory untuk menyimpan pola yang sudah bergabung. Intinya adalah alpha nodes mengevaluasi kondisi dan beta nodes yang menentukan hasil persilangan produk untuk sebuah aturan.

Tabel 1. Bingkai Nama Mobil Merk Suzuki

\begin{tabular}{|l|l|}
\hline \multicolumn{2}{|c|}{ BINGKAI NAMA MOBIL MERK SUZUKI } \\
\hline Tipe Mobil & \multicolumn{1}{|c|}{ Nama Mobil } \\
\hline City Car & New Splash \\
\hline SUV & Grand Vitara 2.4 \\
\hline $\begin{array}{l}\text { Commercial } \\
\text { Car }\end{array}$ & $\begin{array}{l}\text { Mega Carry Xtra } \\
\text { Mega Carry } \\
\text { Carry 1.5 Real Van } \\
\text { Carry 1.5 Futura Pick Up }\end{array}$ \\
\hline $\begin{array}{l}\text { Compact } \\
\text { MPV }\end{array}$ & Karimun Wagon \\
\hline Hatch Back & Swift \\
\hline MPV Bonet & Ertiga \\
\hline MPV & AVP \\
\hline
\end{tabular}

\subsection{PHP (Perl hypertext Preprocessor}

Menurut Arief (2011), PHP (Perl Hypertext Preprocessor)m adalah bahasa server-side-scripting yang menyatu dengan HTML untuk membuat halaman web yang dinamis". Dengan menggunakan program PHP, sebuah website akan lebih interaktif dan dinamis. Adapun kelebihan-kelebihan dari PHP yaitu:

1. PHP merupakan sebuah bahasa script yang tidak melakukan sebuah kompilasi dalam penggunaannya. Tidak seperti halnya bahasa pemrograman aplikasi yang lainnya.

2. PHP dapat berjalan pada web server yang dirilis oleh Microsoft, seperti IIS atau PWS juga pada apache yang bersifat open source.

3. Karena sifatnya yang open source, maka perubahan dan perkembangan interpreter pada PHP lebih cepat dan mudah, karena banyak milis milis dan developer yang siap membantu pengembanganya.

4. Jika dilihat dari segi pemahaman, PHP memiliki referensi yang begitu banyak sehingga sangat mudah untuk dipahami.

5. PHP dapat berjalan pada 3 operating sistem, yaitu: Linux, unux, dan windows, dan juga dapat dijalankan secara runtime pada suatu console.

\subsection{MySql}

Menurut Arief (2011), MySQL adalah salah satu jenis database server yang sangat terkenal dan banyak digunakan untuk membangun aplikasi web yang menggunakan database sebagai sumber dan pengolahan datanya.

\section{RANCANGAN SISTEM}

Pada gambar 3 dibawah merupakan diagaram alir program sistem pakar diagnose kerusakan mobil Suzuki yang dimulai dari login dari pengguna atau mekanik, apabila belum terdaftar sebagai mekanik maka harus daftar terlebig dahulu sebagai mekanik agar bisa masuk sebagai mekanik untuk melakukan diagnosa kerusakn mobil Suzuki. Jika mekanik sudah terdaftar maka mekanik bisa masuk kedalam sistem dan menginputkan gejala yang ada pada mobil Suzuki agar bisa diproses untuk mendapatkan solusi dari kerusakan mobil dan selesai.

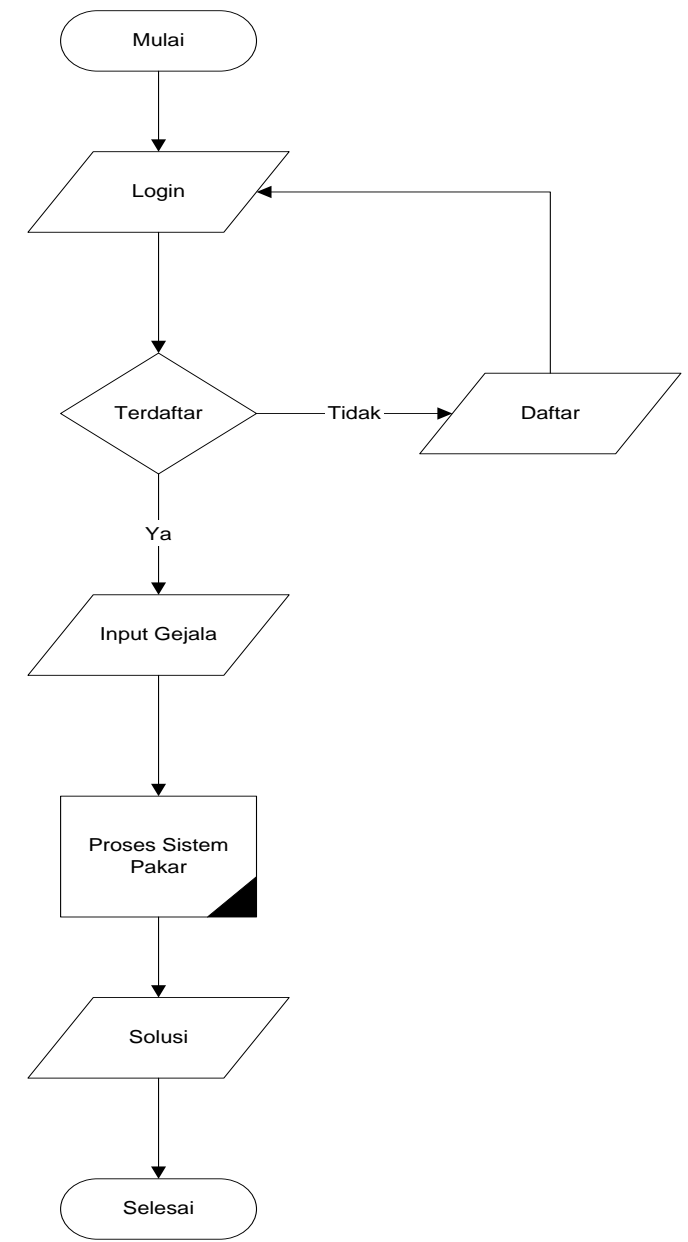

Gambar 3. Flowchart Program

Pada gambar 4 dibawah merupakan diagaram alur Algoritma RETE dari gambar dibawah kita bisa melihat alur algoritma RETE dimulai dari mobil atau mekanik mobil menginputkan gejala kerusakan dengan kesimpulan, jika gejala kerusakan mobil Suzuki G1 maka kerusakannya berupa P1, dan jika kerusakannya P1 maka solusi dari kerusakan mobil Suzuki adalah S1. Hal ini berlaku pada gejala kerusakan selain G1, missal G2, G3, G4 dan seterusnya maka akan menemukan kode 
kerusakan sesuai dengan gejala yang diinputkan, jika sudah ditemukan kode kerusakan maka secara otomatis akan menemukan hasil atau solusi dari kerusakan mobil sesuai dengan kerusakan yang terjadi pada mobil Suzuki.

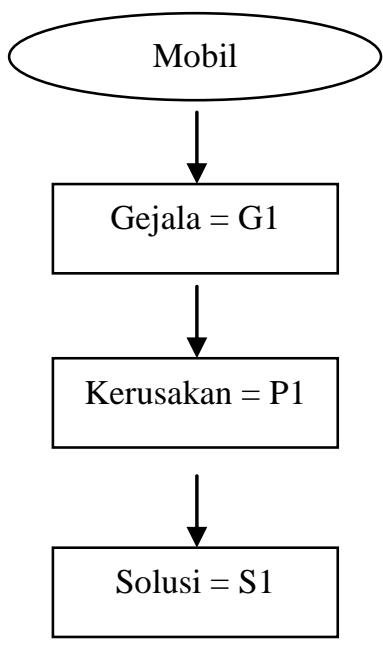

\section{Gambar 4. Diagram Alur Algoritma RETE}

\section{IMPLEMENTASI}

Gambar-gambar dibawah ini merupakan Algoritma RETE dari gejala kerusakan mobil Suzuki:

1. Bingkai Gejala Kerusakan pada Mesin

Tabel 2. Bingkai Gejala Kerusakan pada Mesin

\begin{tabular}{|l|l|}
\hline \multicolumn{2}{|c|}{ BINGKAI GEJALA KERUSAKAN } \\
MOBIL SUZUKI \\
Nama & $\begin{array}{l}\text { Kerusakan ringan.(P1) } \\
\text { Kerusakan } \\
\text { Kerusakan sedang.(P2) }\end{array}$ \\
\hline $\begin{array}{l}\text { Gejala } \\
\text { Kerusakan.(P3) }\end{array}$ & $\begin{array}{l}\text { Mesin mobil sulit dinyalakan saat } \\
\text { dingin.(G1) } \\
\text { Mesin mobil sulit dinyalakan saat } \\
\text { panas.(G2) } \\
\text { Mesin sering hidup-mati tidak }\end{array}$ \\
jelas.(G3) \\
Lampu indikator \\
menyala.(G4) \\
Tenaga mesin melemah.(G5) \\
Mesin menggelitik.(G6) \\
$\begin{array}{l}\text { Suara mesin berisik.(G7) } \\
\text { Mesin tersendak setiap kali gas } \\
\text { diinjak.(G8) }\end{array}$ \\
\hline Solusi \\
Kerusakan & $\begin{array}{l}\text { cek aliran listrik atau voltage } \\
\text { kebagian aki kemungkinan } \\
\text { terminal aki yang kendur, kotor } \\
\text { dan berkarat.(S1) } \\
\text { cek salah satu komponen dalam } \\
\text { mesin kemungkinan ada yang } \\
\text { putus, sehingga penghubung } \\
\text { antara starter kebagian mesin } \\
\text { tidak optimal.(S2) } \\
\text { cek pada alternator, aki, ataupun } \\
\text { kabel terminal aki yang kendur, } \\
\text { rusak ataupun putus. selain itu }\end{array}$ \\
\hline
\end{tabular}

\begin{tabular}{|l|l|}
\hline cek juga pada bagian \\
pengapian.(S3) \\
terjadi ketidakcocokan oli \\
dengan tipe mobil, selain itu \\
ukuran volume oli yang tidak \\
sesuai dengan yang dianjurkan \\
pabrik atau oli sudah aus atau \\
habis, sebaiknya ganti dengan oli \\
yang baru.(S4) \\
Cek pada bagiab timing belt, \\
filter bahan bakar hingga \\
regulator tekanan bahan \\
bakar.(S5) \\
bahan bakar tidak sesuai dengan \\
tipe mobil. misal seharusnya \\
menggunakan pertamax malah \\
diberi premium. tingkat RON \\
(research Octane Number) yang \\
tidak cocok.(S6) \\
cek pada bagian Exhaust \\
manifold, selang vacuum, gasket \\
dan kepala silinder.(S7) \\
Cek busi, aliran listrik \\
busi,karburator, aki, throttle \\
body, selang vacuum dan \\
injektor mobil.(S8)
\end{tabular}

Gambar-gambar dibawah ini merupakan tampilan sistem program:

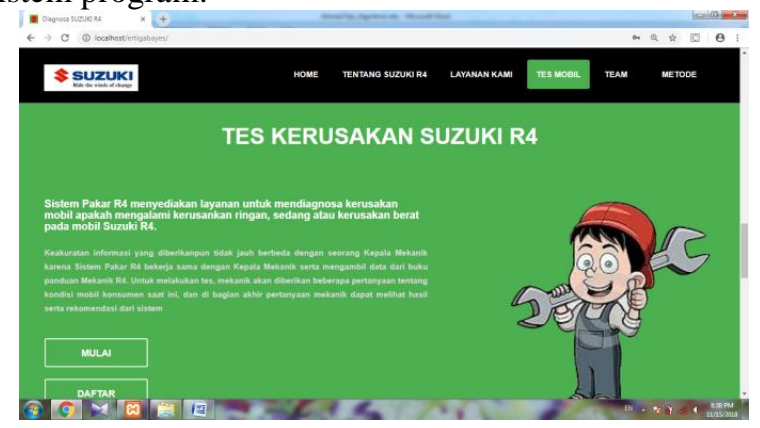

Gambar 5. Tampilan tes kerusakan suzuki

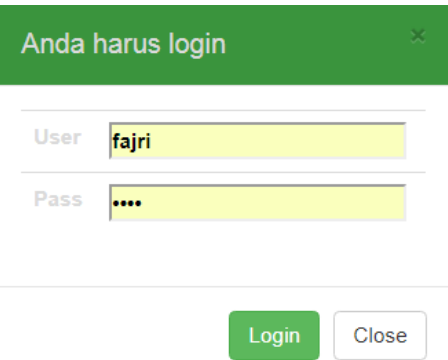

Gambar 6. Tampilan menu login 


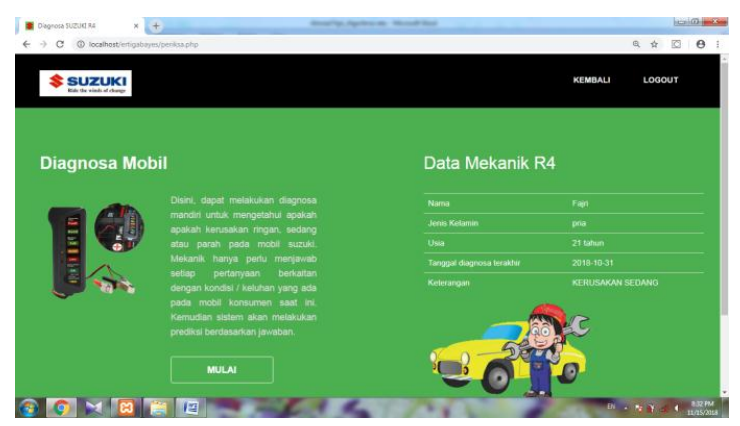

Gambar 7. Tampilan diagnosa kerusakan

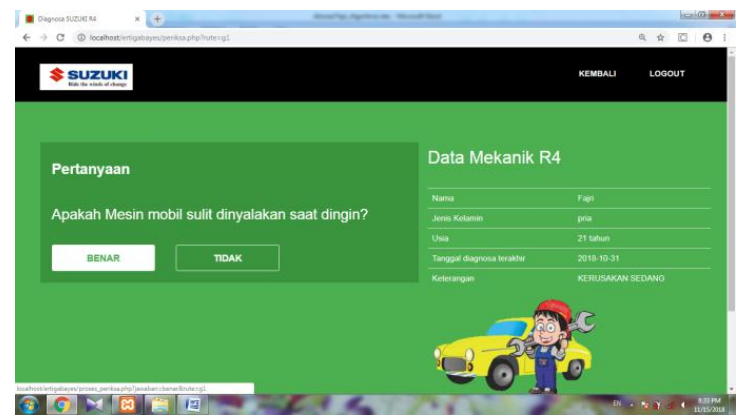

Gambar 8. Tampilan pertanyaan gejala kerusakan

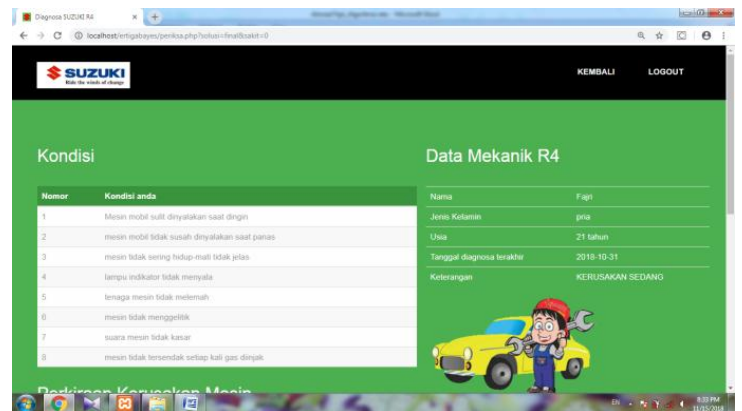

Gambar 9. Tampilan kondisi mobil setelah diagnosa kerusakan

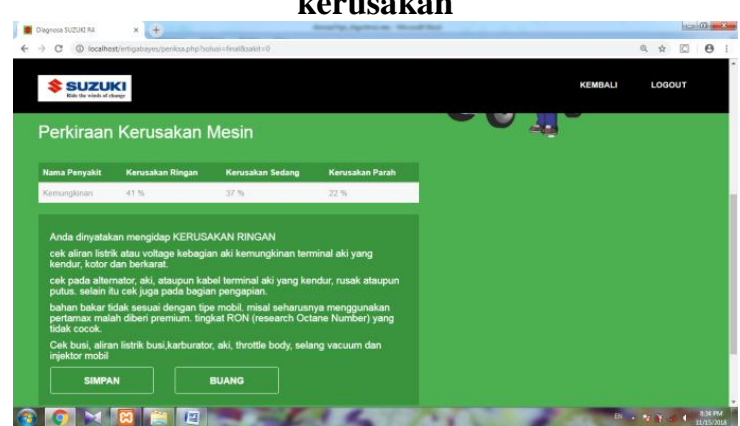

Gambar 10. Tampilan hasil perkiraan kerusakan mesin.

\section{KESIMPULAN}

Berdasarkan uraian dari masing-masing bab dan hasil pembahasan maka dapat diambil kesimpulan sebagai berikut:

1. Sistem pakar untuk mendiagnosa kerusakan Mobil Suzuki termasuk perlindungan cara kuratif, yaitu suatu usaha atau tindakan yang dilakukan setelah Mobil Suzuki itu mengalami gejala-gejala dari kerusakan untuk mempermudah mekanik baru dan orang awam.

2. Diagnosa hanya dengan melakukan pemilihan gejala yang terjadi pada Mobil Suzuki, Sehingga memudahkan dalam penggunaan sistem pakar ini.

3. Akuisisi pengetahuan sistem pakar untuk diagnosa kerusakan pada Mobil Suzuki ini bersumber dari wawancara dengan seorang ahli dalam bidang mekanik mobil, dan informasi dari internet.

4. Dari segi keamanan data, sistem pakar untuk diagnosa kerusakan Mobil Suzuki ini hanya pakar yang diberi hak akses login pakar untuk akuisisi pengetahuan.

\section{SARAN}

Dengan adanya Sistem Pakar untuk Menemukan Penyebab Kerusakan pada Mobil Suzuki dengan Metode Algoritma RETE ini diharapkan mampu memberikan manfaat bagi mekanik dan pelanggan. Untuk mendapatkan manfaat yang maksimal, maka penulis mengajukan beberapa saran sebagai pertimbangan antara lain :

1. Sistem pakar untuk Mobil Suzuki ini perlu ditambahkan data berupa jenis kerusakan, gejalagejala kerusakan, dan cara memperbaiki kerusakan selain yang sudah ada didalam database agar hasil identifikasi yang diperoleh semakin akurat.

2. Bagian-bagian kerusakan pada mobil Suzuki dapat dikembangkan menjadi Algoritma RETE yang lebih terperinci lagi misalnya bisa lebih meluas, bukan hanya mencakup mesin saja tetapi kebagian lain juga seperti: Suspensi, Roda, Ban, Rem, dan Kemudi

3. Untuk penambahan data pengetahuan tidak hanya terfokus kepada satu orang pakar, diharapkan lebih dari satu pakar agar data-data untuk hasil diagnosa lebih baik.

Sistem ini diharapkan nantinya dapat dikembangkan lagi ke sistem yang lebih efisien, misalnya sistem berbasis mobile yang dapat di akses dalam sebuah handphone untuk menggunakan sistem aplikasi ini.

\section{DAFTAR PUSTAKA}

Arief M Rudianto, 2011, Pemprograman Web Dinamis Menggunakan PHP dan MySQL, Andi Offset, Yogyakarta.

Hayadi, B. H. 2018. Sistem Pakar. Deepublish.

Irwansyah, E., \& Moniaga, J. V. 2014. Pengantar Teknologi Informasi. deePublish.

Peter F.J. Lucas \& Linda J. Van der Gaag, 1991, Principles of Expert Systems, Amsterdam : Penerbit Addison-Wesley.

Rukun, K., \& Hayadi, B. H. 2018. Sistem Informasi Berbasis Expert System. Deepublish.

SIS, PT, 2012, Suzuki Ertiga: Pedoman Perbaikan, Jakarta: PT. Suzuki Indomobil Sales 2012. S

Sutabri, Tata, 2012. Analisa Sistem Informasi. Yogyakarta : Andi. 
Turban Efraim, 2010, Mesin Inferensi dan Tahapan Pengembangan Sistem Pakar,Yogyakarta : Penerbit Andi Offset.

Ukkas, M. I., Palupi, S., \& Pradiba, I. 2014. Sistem Pakar Diagnosa Jenis-jenis Penyakit Demam Panas pada Balita dengan Menggunakan Metode Fuzzy Logic Berbasis Web. Sebatik, 12(1), 24-30.

Ukkas, M. I., Yulsilviana, E., \& Aisyah, S. 2012. Sistem Pakar Untuk Mendiagnosa Kecenderungan Perilaku Abnormal Pada Anak-anak Menggunakan Metode Bayes. Sebatik, 8(1), 3033. 